\title{
OPTIMAL DESIGN OF CONVENTIONAL WAREHOUSEFLOORS: CONCRETE FLOORING SOLUTIONS AND RACKING ANCHORS
}

\author{
Janis Locmanis ${ }^{1}$, Bradley J. Pease ${ }^{1}$, Rolands Cepuritis ${ }^{2}$ \\ ${ }^{1}$ SIA "PRIMEKSS", Latvia; ${ }^{2}$ Norwegian University of Science and Technology, Norway \\ janis.locmanis@primekss.com, bradley.pease@primekss.com, \\ rolands.cepuritis@ntnu.no
}

\begin{abstract}
In modern industrial warehouses, the concrete flooring slab is one of the main total cost components. Thus, designers of these structures are under a constant pressure to reduce the total slab cost, while maintaining the expected functionality and durability of the slab. Due to technological progress in last decades and innovations in the concrete industry, it is now possible to produce steel fiber reinforced self-stressing concrete (SFRSSC) floors, which are far thinner, while providing various advantages and performance improvements compared to traditional concrete floors [1]. One key aspect of warehouse floor design impacted by reductions in slab thicknesses is the design and detailing of anchors for warehouse racking systems. Commonly available design aids for anchors from suppliers have focused on embedment of anchors in traditional concrete floors, ignoring any potential benefits from embedment in SFRSSC floors. As reported in reference [2], a large series of anchor pullout tests was recently completed on SFRSSC samples to develop characteristic design values for this new material combination. These results are utilized in this paper to complete a technological and economic comparison of alternative design solutions for three different example warehouse situations. For all examples, $20200 \mathrm{~m}^{2}$ storage warehouses are assumed with load levels varying from a "lightly loaded" (60 kPa) warehouse, a 'heavily loaded' $(160 \mathrm{kPa})$ warehouse, and a high-bay warehouse. In the design examples, floors are designed according to the guideline TR34 for fiber reinforced concrete and ACI standard for plain concrete floors. Anchor pull out capacity data are obtained from tests and the Fastening Technical Manual (FTM). As presented herein, overall costs for the SFRSSC floor provide significant economic advantages due to reduced volume of concrete and associated reductions in production costs provided by a reduced slab thickness for the same loading. Comparison of the racking anchor detailing includes a limited direct cost impact of SFRSSC floors. Shorter anchors used for SFRSSC floors allow for faster installation per anchor.
\end{abstract}

Keywords: SFRC, racking, anchor, warehouse, slab.

\section{Introduction}

Steel fiber reinforced self-stressing concrete is a composite material type consisting of various types of materials and as a result giving thin jointless floors with enhanced properties. A patent on such flooring and raft slab structure is held by Primekss and marketed as the PrīmX slab system [3].

Concrete as a material is very complex and is subjected to multiple challenges. Some of them are created by shrinkage causing concrete to change in volume and leading to problems as cracks, curling, extensive opening of construction joints, damaged saw-cut joints etc. The common and well-known way to solve shrinkage caused problems in unreinforced slabs is to make saw cut joints with an approximate distance $6 \times 6 \mathrm{~m}$, saw cutting to depth of $1 / 3$ slabs height and adding a slip-sheet under when necessary. This method helps avoid detrimental uncontrolled cracking. Such solution comes with a greater thickness, thousands of meters of saw-cutting, joint filling and additional repair works after the slabs have been put into service. Another potential way to increase the slab capacity and reduce the thickness is by providing steel mesh in the bottom layer. Such a solution still requires dense jointing to deal with random cracking and also includes higher manpower with high health and safety hazards.

SFRSSC is providing a solution to the mentioned problems by means of a) replacing of steel reinforcing bars with steel fibers for required tensile and flexural load capacities $[4 ; 5]$ and b) control of concrete shrinkage with proprietary admixtures[6]. This type of solution is providing elimination of saw cut joints and allows making slabs with the field sizes up to $7000 \mathrm{~m}^{2}$, as well as decreasing the floor thickness and total concrete volume on projects due to material properties.

More importantly, these enhancements are fundamental for warehouse functions providing a smooth surface for forklift operations and rigid foundation for racking systems to store the goods.

This paper seeks to provide a comparison of the technological and economic impacts provided by conventional material solutions (including reinforced and unreinforced concrete) and by the SFRSSC 
concrete approach as to ascertain an optimal design for conventional warehouse slabs including the determination of the anchor impact.

\section{Materials and methods}

To evaluate the optimal design solution, three typical warehouse situations are considered:

- Case I - "Lightly loaded" warehouse;

- Case II - "Heavily loaded" warehouse;

- Case III - High-bay warehouse.

In each case the size of warehouse is assumed to be $20200 \mathrm{~m}^{2}$.

Loads for each specific case can be slightly different and the loads represented in Table 1 are chosen from typical implemented projects. The loads represented in Table 1 are assumed to be the main characteristics governing the design of the slab, thus the subbase and subgrade are of a good quality. Required anchor load capacity is freely assumed for these case studies.

Table 1

Design cases

\begin{tabular}{|c|c|c|c|}
\hline \multirow{2}{*}{ Design inputs } & \multicolumn{3}{|c|}{ Design case } \\
\cline { 2 - 4 } & I - Lightly loaded & II - Heavily loaded & $\begin{array}{c}\text { III - High-bay } \\
\text { warehouse }\end{array}$ \\
\hline $\begin{array}{c}\text { Uniform distributed loading, } \\
\mathrm{kN} \cdot \mathrm{m}^{-2}\end{array}$ & 60 & 120 & 130 \\
\hline Forklift load, $\mathrm{kN}$ & Wheel load 32 & Wheel load 70 & Wheel load 70 \\
\hline $\begin{array}{c}\text { Back-to-back rack leg load } \\
\text { level, } \mathrm{kN}\end{array}$ & $70(140)$ & $130(260)$ & $140(280)$ \\
\hline $\begin{array}{c}\text { Required anchor load capacity, } \\
\text { design action } S_{d}, \mathrm{kN}\end{array}$ & 25 & 50 & 75 \\
\hline
\end{tabular}

Further, for each of the warehouse type three material types are chosen and the necessary thickness designed, material amounts determined. General material type information is provided in Table 2, showing the concrete compressive strength, used reinforcement, assumed subgrade reaction and the utilized code for designing the slab.

Table 2

Slab material parameters used in design

\begin{tabular}{|c|c|c|c|}
\hline \multirow{2}{*}{ Design input values } & \multicolumn{3}{|c|}{ Material Type } \\
\cline { 2 - 4 } & $\begin{array}{c}\text { Unreinforced } \\
\text { concrete }\end{array}$ & $\begin{array}{c}\text { Reinforced } \\
\text { concrete }\end{array}$ & SFRSSC \\
\hline Design compressive strength & C25/30 & C25/30 & C25/30 \\
\hline $\begin{array}{c}\text { Details on reinforcement } \\
\text { properties }\end{array}$ & No reinforcement & $\begin{array}{c}\text { Steel mesh } \\
\varnothing 8 / 150 / 150\end{array}$ & $\begin{array}{c}\text { Steel fibers HE } \\
75 / 50 \text { of } 1200 \mathrm{MPa} \\
\text { tensile strength }\end{array}$ \\
\hline $\begin{array}{c}\text { Assumed subgrade } \\
\text { characteristics, modulus of } \\
\text { subgrade reaction } \boldsymbol{k}_{\text {sub }}, \mathrm{N} \cdot \mathrm{mm}^{-3}\end{array}$ & 0.083 & 0.083 & 0.083 \\
\hline Thickness I & $210 \mathrm{~mm}$ & $170 \mathrm{~mm}$ & $90 \mathrm{~mm}$ \\
\hline Thickness II & $315 \mathrm{~mm}$ & $230 \mathrm{~mm}$ & $150 \mathrm{~mm}$ \\
\hline Thickness III & - & $245 \mathrm{~mm}$ & $170 \mathrm{~mm}$ \\
\hline Utilized design code & ACI360R-10[7] & TR34 $4^{4 \mathrm{th}}[8]$ & TR34 $34^{4 \text { th }}[8]$ \\
\hline
\end{tabular}

Overview of a typical warehouse plan with racking and floor layoutis shownin Figure 1.

For an economical comparison screw anchors Hilti HUS3-H are assumed with sizes according to loads and the floor material type. The load characteristics for SFRSSC are taken from recent research "Determination of screw anchor capacity in ultra-thin steel fiber reinforced self-stressing concrete (SFRSSC) flat slabs" [2]. Pullout strength is determined according to the European Assessment 
Documents (EAD) [9; 10]. The determined anchor properties using Hilti Profis Anchor software are gathered in Table 3. It was observed that in individual cases the anchor pullout strength was higher in SFRSSC, but after analysis of the results, it showed equivalent results in the tension $N_{R k}$ and in shear $V_{R k}$. Thus, huge improvement was observed in anchor spacing and edge distances due to better local material SFRSSC properties. It was observed that the cone of concrete breakout is much smaller. These observations allow for thinner base material. For this reason, for the same load $E_{d}$ in each material (assuming both are uncracked) can be the same anchor and typical baseplate solution, but the base material and spacing are rather limited and need to follow the anchor producer FTM $[9 ; 11]$ guidelines for anchoring in specific material type.As an example, if the racking designer determines an anchor HUS3-H with a diameter $\varnothing 8$, embedment $h_{n o m}=70 \mathrm{~mm}$, the required base material for the reinforced slab will be higher than SFRSSC and thus giving economy on material. Comparing only limitation for the base material, it can be approximately $20 \mathrm{~mm}$ less for SFRSSC.

Regarding unreinforced concrete slab material, it is assumed to be cracked and therefore anchoring properties are reduced, what is also visible in Table 3. Unreinforced concrete slab requires bigger anchors and also bigger thickness for the base material.

a)

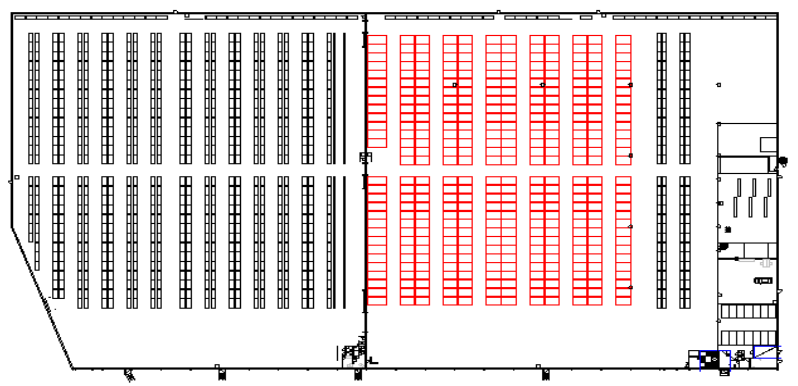

b)

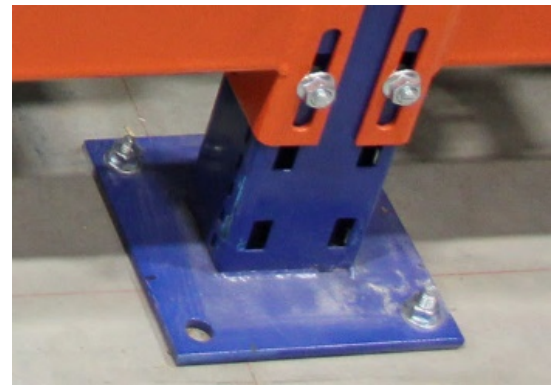

Fig. 1. Typical warehouse racking layout (a) and racking baseplate (b)

The base material thickness and anchor testing in SFRSSC fulfils the requirements for the European Assessment Documents Guidelines (ETAG). On that basis, it is possible to implement more economical solutions for warehouses allowing anchor racking in thinner slabs.

Table 3

Anchor material parameters used in technical and economical comparison

\begin{tabular}{|c|c|c|c|c|c|c|c|c|c|}
\hline \multirow{3}{*}{$\begin{array}{l}\text { Design input } \\
\text { values }\end{array}$} & \multicolumn{9}{|c|}{ Design case } \\
\hline & \multicolumn{3}{|c|}{ I - Lightly loaded } & \multicolumn{3}{|c|}{ II - Heavily loaded } & \multicolumn{3}{|c|}{$\begin{array}{c}\text { III - High-bay } \\
\text { warehouse }\end{array}$} \\
\hline & Unr. & Reinf. & $\begin{array}{c}\text { SFRS } \\
\text { SC }\end{array}$ & Unr. & Reinf. & $\begin{array}{c}\text { SFRS } \\
\text { SC }\end{array}$ & Unr. & Reinf. & $\begin{array}{c}\text { SFRS } \\
\text { SC }\end{array}$ \\
\hline $\begin{array}{l}\text { Recommended } \\
\text { load for one } \\
\text { anchor } N_{R d}, \mathrm{kN}\end{array}$ & 9.4 & - & 7.6 & 15.1 & - & 13.2 & - & - & 21.2 \\
\hline $\begin{array}{l}\text { Pullout strength } \\
\text { obtained from } \\
\text { testing in } \\
\text { SFRSSC } \\
(\mathrm{C} 25 / 30) \text { for one } \\
\text { anchor } N_{R k}, \mathrm{kN} \\
\end{array}$ & - & - & 16 & - & - & 27.8 & - & - & 44.4 \\
\hline $\begin{array}{c}\text { Anchor type, } \\
\text { HUS3-H }\end{array}$ & $\begin{array}{l}10 \mathrm{x} \\
100 \\
\end{array}$ & $\begin{array}{c}8 \mathrm{x} \\
100\end{array}$ & $\begin{array}{l}8 x \\
85 \\
\end{array}$ & $\begin{array}{l}14 x \\
130 \\
\end{array}$ & $\begin{array}{l}10 \mathrm{x} \\
110\end{array}$ & $\begin{array}{l}10 \mathrm{x} \\
100 \\
\end{array}$ & $\begin{array}{l}\text { HST } \\
\text { M20 }\end{array}$ & $\begin{array}{l}14 \mathrm{x} \\
150 \\
\end{array}$ & $\begin{array}{l}14 \mathrm{x} \\
130 \\
\end{array}$ \\
\hline $\begin{array}{c}\text { Anchor } \\
\text { embedment, } \mathrm{mm}\end{array}$ & 67 & 85 & 55 & 92 & 95 & 85 & 120 & 135 & 115 \\
\hline
\end{tabular}

To find an optimal design, the costs were determined for slab types covered in Table 2 . These cost estimates cover 8 individual cases regarding the material type and load. Cost estimation includes basic 
$\underline{\text { materials, }}$ equipment, labor and anchors. Other minor positions and traveling costs are not covered here, as those may vary for each specific case.

For this comparison anchors are included to show the cost influence on the general prime cost. Summary of costs for separate positions are covered in Table 4.

Material cost estimates, based on internal data on typical median costs in the Scandinavian market, where appropriate, labor costs are included;

Table 4 costs are in Euro and expressed for total volume

\begin{tabular}{|c|c|c|c|c|c|c|}
\hline \multicolumn{2}{|c|}{ Estimated position } & \multirow{2}{*}{$\begin{array}{c}\text { Site- } \\
\text { delivered } \\
\text { and placed } \\
\text { concrete, } \\
\text { EUR }\end{array}$} & $\begin{array}{c}\text { Reinforce- } \\
\text { ment/fibers, } \\
\text { EUR }\end{array}$ & $\begin{array}{c}\text { Labor, } \\
\text { EUR }\end{array}$ & \multicolumn{2}{c|}{$\begin{array}{c}\text { Anchors, \% of } \\
\text { self-cost, EUR }\end{array}$} \\
\cline { 1 - 3 } $\begin{array}{c}\text { Floor type and } \\
\text { thickness, mm }\end{array}$ & Design case & $\begin{array}{c}\text { Anchors } \\
\text {, EUR }\end{array}$ & $\begin{array}{c}\text { 4 anch., } \\
\text { \% }\end{array}$ \\
\hline SFRSSC, 90 mm & Thickness I & 245181 & 81434 & 38355 & 9791 & 2.1 \\
\hline SFRSSC, 150mm & Thickness II & 383370 & 127332 & 51212 & 12987 & 1.9 \\
\hline SFRSSC, 170mm & Thickness II & 434486 & 144310 & 57320 & 44499 & 5.7 \\
\hline Reinf., 170mm & Thickness I & 384065 & 110877 & 66617 & 10594 & 1.6 \\
\hline Reinf., 230mm & Thickness II & 519618 & 110877 & 79494 & 15475 & 1.9 \\
\hline Reinf., 245mm & Thickness II & 553506 & 110877 & 82713 & 51500 & 5.8 \\
\hline Plain, 210mm & Thickness I & 474434 & 2888 & 72598 & 12987 & 2.0 \\
\hline Plain, 245mm & Thickness II & 553506 & 2888 & 80109 & 235041 & 24 \\
\hline
\end{tabular}

\section{Results and discussion}

The estimated self-costs for each case are summarized in Table 5. Based on the cost estimation made for various types of floors, it is visible that the SFRSSC floor design is most cost competitive between other various designs. Concrete has the biggest impact on overall prime cost in the range of $45 \%$ to $74 \%$, depending on the type of the floor. This explains the difference in overall costs of the floor. A large portion of costs include work, which can vary $8 \%$ to $11 \%$ and reinforcement $\sim 15 \%$.

Comparing the type of anchors and general influence on cost, it is observed that it is possible to achieve some level of economy in smaller scale, seeing that the anchor overall cost on the project can vary by thousands of euro, depending on the design case and specific scale of warehouse and racking layout.

Including the previously mentioned screw anchors in Table 3 for SFRSSC, it is possible to install thinner base material and provide savings on material costs. In estimation are assumed 4 anchors per racking leg, what is more than needed, under smaller loads it would be sufficient with 2 anchors and reducing the cost twice. The cost of anchors compared to total prime cost is very small (except one case study, where it was not sufficient to use HUS3-H anchors for such high loads in plain concrete), and referring to Table 4, the anchor influence can vary from $1.5 \%$ up to $6 \%$, depending on the type of fixture solution and exposed loads from racking.

Table 5

Economic overview of various warehouse types and material solutions

\begin{tabular}{|c|c|c|c|}
\hline \multirow{2}{*}{ Warehouse type } & \multicolumn{3}{|c|}{ Total estimated costs (EUR) } \\
\cline { 2 - 4 } & $\begin{array}{c}\text { Unreinforced } \\
\text { concrete }\end{array}$ & $\begin{array}{c}\text { Reinforced } \\
\text { concrete }\end{array}$ & SFRSSC \\
\hline Lightly loaded & 648242 & 667370 & 469664 \\
\hline Heavily loaded & 956880 & 820680 & 677113 \\
\hline High-bay & - & 893812 & 782949 \\
\hline
\end{tabular}

Table 6 provides basic advantages and challenges for each of the design cases covered previously to better understand how the solution affects the technical and economical side of the project. 
Overview of technological advantages and challenges associated with various combinations of warehouse type and material solution

\begin{tabular}{|c|c|c|c|c|}
\hline \multirow{2}{*}{\multicolumn{2}{|c|}{ Warehouse type }} & \multicolumn{3}{|c|}{ Material solution } \\
\hline & & $\begin{array}{l}\text { Unreinforced } \\
\text { concrete }\end{array}$ & $\begin{array}{l}\text { Reinforced } \\
\text { concrete }\end{array}$ & SFRSSC \\
\hline \multirow{2}{*}{$\begin{array}{l}\text { Lightly } \\
\text { loaded, } \\
\text { heavily } \\
\text { loaded, } \\
\text { high- } \\
\text { bay }\end{array}$} & Advantages & $\begin{array}{l}\text { Simple process } \\
\text { Limited } \\
\text { equipment }\end{array}$ & $\begin{array}{l}\text { Relatively simple } \\
\text { process. Higher } \\
\text { load bearing } \\
\text { capacity than } \\
\text { unreinforced } \\
\text { concrete. }\end{array}$ & $\begin{array}{l}\text { Better material properties. } \\
\text { Assumed to be uncracked. } \\
\text { Improved setting parameters } \\
\text { for anchors. Thin jointless } \\
\text { floor solution. Less time } \\
\text { consumed on adding fibers } \\
\text { and preparing day-joints. }\end{array}$ \\
\hline & Challenges & $\begin{array}{c}\text { Saw-cutting } \\
\text { Great length and } \\
\text { number of joints. } \\
\text { Potential for } \\
\text { cracks and } \\
\text { curling. High } \mathrm{CO}_{2} \\
\text { footprint. }\end{array}$ & $\begin{array}{c}\text { Saw-cutting } \\
\text { Length and } \\
\text { number of joints. } \\
\text { More hours spent } \\
\text { on reinforcement } \\
\text { preparation. }\end{array}$ & $\begin{array}{l}\text { Various equipment and } \\
\text { operations involved. }\end{array}$ \\
\hline
\end{tabular}

\section{Conclusions}

1. SFRSSC provides economy due to two factors: a) lower base material thickness needed for the anchors (acc. to FTM and approximately down by $20 \mathrm{~mm}$ ) and reduced total slab thickness due to higher load bearing capacity(by $80 \mathrm{~mm}$ lower total slab thickness comparing to reinforced concrete).

2. Anchor influence on cost is relatively limited and vary from $1.5 \%$ to $6 \%$, but with accuracy to detailing anchors and in combination with SFRSSC, it was possible to achieve a more cost competitive solution and saving on anchors approximately from 800 EUR up to 7000 EUR, depending on chosen slab solution.

\section{Acknowledgements}

In accordance with the contract No. 1.2.1.1/18/A/007 between "VMKC" Ltd. and the Central Finance and Contracting Agency, the study is conducted by "Primekss" Ltd. with support from the European Regional Development Fund (ERDF) within the framework of the project "Competence centre of smart materials and technologies".

\section{References}

[1] Chemically Post-Tensioned Ultrathin Joint free Fibre Reinforced concrete with Zero Shrinkage on Grade and on Piles. X.Destrée, R.Cepuritis. Advances in Cement and Concrete Technology in Africa, ACCTA 2016 Symposium (January 2016), Dar Es Salaam, Tanzania.

[2] Cepuritis R., Pease B., Locmanis J. Determination of screw anchor capacity in ultra-thin steel fiber reinforced self-stressing concrete (SFRSSC) flat slabs, 19th International Scientific Conference, Engineering for Rural Development, 20 -22 May, year 2020, Jelgava, Latvia, pp. 536-540.

[3] Ošlejs J., Kravalis K. "Composite concrete for floor slabs and rafts," US Patent application US2012/0021206 A1, 2012, 6 p.

[4] Steel fibre Reinforcing against Cracking and for Structural Applications. X.Destrée, Swedish concrete Association, University of Lund, Sweden, Nov.16, 2011.

[5] Fibres in Concrete. X.Destrée. The Institution of Structural Engineers, Birmingham, 28th april 2009. 
[6] Destrée X., Pease B. Reducing $\mathrm{CO}_{2}$ Emissions of Concrete Slab Constructions with the PrimeComposite Slab System. American Concrete Institute (ACI) Special Publication 299, 2015, pp. 1-12.

[7] ACI 302.1R-04."Guide for Concrete Floor and Slab Construction", lpp. 34-61

[8] TR34 - Concrete Industrial Ground Floors - Concrete Society Working Party - $4^{\text {th }}$

[9] European Organization for Technical Assessment, "European Assessment Document EAD 330011-00-0601 - Mechanical Fasteners for use in Concrete," October 2016.

[10] European Organization for Technical Assessment, "European Assessment Document EAD 330232-00-0601 - Adjustable Concrete Screws," March 2015.

[11] Technical data sheet HUS3-H-PrīmX. 